\title{
Aspectos históricos de microtoponímia no Brasil
}

Maria Vicentina de Paula do Amaral Dick

Departamento de Linguística e Línguas Orientais - FFLCH/USP

De um modo geral, as relações Toponímia e História se fazem sentir no quotidiano dos próprios fatos que os designativos revelam. O lado dinâmico da disciplina onomástica não poderia deixar à parte ocorrências e nomes particulares, pelo simples motivo de não terem alcançado, ainda, uma grande amplitude de emprego. Muitas vezes, saliente-se, é a difusão mais ou menos rápida e nítida, num contexto geográfico específico, que confere a um topônimo dimensões maiores que a sua própria regionalidade ou o seu conteúdo significativo.

É certo que há os que já nascem assim, enriquecidos pela circunstância que designam, de repercussão generalizada; são os portadores do que se poderia chamar de "espírito coletivo", verdadeiramente carismáticos, trazendo consigo uma carga histórico-social bastante ampla. Quantos deles não se fazem presentes em todos os tipos de comunidades e acidentes, desde as pequenas vilas até as grandes metrópoles, em simples becos e travessas ou em monumentos públicos, nos pequenos cursos d'água ou nos caudais mais volumosos. Neste emprego reiterado de topônimos idênticos, está evidenciada, acredito, a razão direta de sua própria capacidade funcional, a transmissão de conhecimentos, realizando, então, dessa forma, 
a Toponímia, os seus objetivos informático-educativos, e atingindo um número considerável de pessoas. A maior ou menor difusão de um termo, dentro desses padrões, dá-lhe um caráter de uso eminentemente nacional, já que pertence à história do país onde se inscreve.

E O que acontece, por exemplo, com a nomeação relativa aos movimentos da Independência do Brasil e da proclamação da República, constante do Indice dos topônimos brasileiros (1). No primeiro caso, Independência distribui-se em acidentes humanos nos Estados do Acre, Ceará, Espírito Santo, Maranhão, Mato Grosso, Pará, Rio Grande do Sul e em um riacho no Ceará. 7 de Setembro aparece, de preferência, em acidentes físicos: cachoeira e rio em Mato Grosso e Rondônia, igarapé neste Estado, ribeirão em São Paulo e rio em Mato Grosso, enquanto o sintagma Sete de Setembro conforma um acidente humano no Rio Grande do Sul. República, no segundo caso, é acidente humano nos Estados do Ache, Amazonas e São Paulo, figurando, também, em um igarapé amazonense. A data da proclamação, 15 de Novembro, nomeia uma cachoeira em Rondônia e um ribeirão em São Paulo, da mesma forma que o sintagma Quinze de Novembro é um acidente humano no Rio Grande do Sul e rio em Minas, Pará e Santa Catarina.

Por outro lado, na série que recorda os presidentes brasileiros, o nome de Getúlio Vargas surge sob várias formas, em diversos acidentes humanos: Presidente Getulio, em Santa Catarina; Getulandia; no Rio de Janeiro; Getulina, em São Paulo e Getulio Dorneles Vargas, no Rio Grande do Sul. Juscelino Kubitschek de Oliveira é outro exemplo de figuração antropotonímica: enquanto o referido Indice registra duas ocorrências em Minas Gerais - Presidente Juscelino e Presidente Kubitschek -, o Dicionário histórico-geográfico de Minas Gerais explicita as referências. Segundo seu autor, no município de Curvelo, a lei $\mathrm{n}^{\circ} .2764$ elevou o distrito de Ponte de Paraúna à categoria de cidade, com o nome de Presidente Iuscelino, ao mesmo tempo em que criava o município de Presidente Kubitschek, em substituição ao distrito de Tijucal. Entretanto, a mesma lei 2764 também elevou o povoado de São José da Lagoa, no mesmo município de Curvelo, a sede distrital, com o nome de $J . K$. Esta forma abreviada revestiria, para ele, uma homenagem "desnecessária e ridícula", como se as siglas famosas envolvessem "marca de um café, automovel ou canivete" (2). A opinião do autor é bastante justificável, desde que a intenção de perpetuar o nome do governante já estava satisfatoriamente cumprida com os dois topônimos mencionados. A Toponímia não deveria, de fato, acobertar finalidades bajulatórias, a fim de que seus objetivos

(1) - Vanzolini, P. E. e Papavero, N. - Indice dos topônimos contidos na carta do Brasil 1:1.000.000. Rio de Janeiro, IBGE, 1968.

(2) - Barbosa, Waldemar de Almeida. - Dicionário histórico-geográfico de Minas Gerais. Belo Horizonte, Promoção da Família Edit., 1971, p. 16. 
últimos e a seriedade de seus conceitos não se deturpem ao longo das exemplificações.

Todavia, é certo que um nome pode se fixar localmente, e nunca ultrapassar, na prática, os limites geográficos de sua região; nem por isso deixará de revestir a feição histórica que se the aponta. Nascem esses denominativos como topônimos meramente locais, refletem dados e pessoas desconhecidas, em geral, do grande público, apesar de terem realizado feitos de realce em seu meio, o que thes deu "condição toponímica" propriamente dita para serem rememoradas, de uma forma ou de outra. Continuam, porém, sendo elementos "despersonalizados" para a maioria da população. Principalmente em grandes extensões territoriais como a nossa, ou em regiões densamente povoadas, onde o conhecimento em pormenor da rede toponomástica se torna difícil, mais se faz sentir essa tipologia denominativa.

A microtoponímica dos municípios e dos bairros paulistanos é um elemento da problemática aqui enunciada. Esclareça-se que os dados relativos a esses ítens são resultantes de dois projetos de pesquisa que vêm sendo desenvolvidos pela secção de Toponímia do Departamento de Línguas Orientais da F.F.L.C.H.: o primeiro, referente aos municípios paulistas, diz respeito a um trabalho conjunto da equipe de professores da área para a elaboração do Atlas Toponímico do Estado de São Paulo, enquanto o segundo relaciona-se ao levantamento da nomenclatura das ruas da cidade de São Paulo. A pesquisa, sob minha orientação, está sendo realizada pelos alunos do curso de graduação nos fichários do Arquivo Municipal, na bibliografia existente e, mesmo, no contacto com informantes, quando necessário.

No município de Tupã, situado na chamada zona da Alta Paulista, o Museu Histórico e o Instituto de Educação da cidade (3), criado em 1951, trazem o nome da India Vanuíre, como homenagem àquela que muito concorreu para a pacificação de sua tribo, a Kaingang, habitante de trechos da região, o que facilitou a instalação da antiga Estrada de Ferro Noroeste. Muito embora o seu papel decisivo para um acontecimento que beneficiaria, indiretamente, a uma porção maior do território pátrio, o Indice dos topônimos não registra outra ocorrência similar, em qualquer acidente geográfico do país. Da mesma maneira, o nome do fundador de Tupã, Luiz de Souza Leão, de conhecida família pernambucana, está circunscrito, como designativo, apenas à história da região.

(3) - A partir de 1966, com as colocações de Henri Dorian e L. Hamelin na $2^{a}$ Confer. das Nações Unidas para normalização e padronização dos nomes geográficos, propondo a alteração do nome da disciplina para Coronímia, face à elasticidade de seu campo de estudos, elementos desta categoria cabem, agora, perfeitamente, no âmbito de pesquisas da Toponímia, sem que se corra o risco de inadequação. 
Situado na mesma área geográfica, Bastos tem seu nome ligado ao do proprietário das terras da qual se originou o município, Henrique Bastos, sendo também topônimo único, segmento a referida fonte.

A origem do nome de São Simão, na zona anteriormente chamada Média Mogiana, por causa da ferrovia, pode ser encontrada na devoção ao apóstolo Simão Cananeu ou Zelote, ou no nome do seu fundador, Simão da Silva Teixeira, que introduziu a imagem do santo na capela a ele dedicada. A avenida Simão da Silva é o local onde ele residia:

"Sabe-se que ele morou na avenida que hoje tem o seu nome, isto é, avenida Simão da Silva Teixeira. Isto parece confirmar a tradição que diz que a capela por ele erigida teria sido no começo dessa rua, perto do atual cemitério, ou mais ou menos na esquina daquela rua com a Joaquim Procópio de Araujo Carvalho" (4).

A toponímia sistemática das ruas de São Simão data de 1880, quando foram ofertadas à Câmara Municipal três placas com os dísticos "rua do Bretas", "rua Comendador Fonseca" e "rua de São José" (5). Com a proclamação da República, tal qual aconteceu em outros municípios (6), surgiram as ruas e homenagem aos republicanos: Rodolfo Miranda, Francisco Glicerio, Quintino Bocaiuva, Campos Sales, Prudente de Moraes, Deodoro da Fonseca e Ruy Barbosa. Dentre a toponímia particular, porém, citem-se: rua do Manoel Dias, "morador em uma chácara no início da referida rua"; rua Francisco Tamborim, "heroi simonense morto na Itália a 24.1.1945, em combate"; rua Alfredo Teixeira Machado, "político e intendente municipal"; rua Ovidio Ciciarelli, "músico e regente da corporação musical", entre outros (7).

Origem denominativa semelhante teve o município de São Manoel, antigo São Manoel do Paraiso, próximo a Botucatu. Seu fundador foi Manuel Gomes de Faria, grande proprietário de terras da região. Em 17 de junho de 1871, "foi oferecido ao local uma capela e invocado para padroeiro o milagroso São Manoel, prestando-se, assim, uma home-

(4) - Oliveira Fausto Pires de. - Elementos para a história de São Simão. 1975 , p. 10 .

(5) - Oliveira, F. Pires de. ibidem, p. 277.

(6) - Em Itapetininga, na região sudoeste do Estado, fundado por volta do Século XVIII pelos sertanistas Simão Barbosa Franco e Salvador do Oliveira Leme, o Sarutaiá, o velho centro da cidade registra também nomes de antigos republicanos e personalidades conhecidas da história nacional, como Campos Sales, Quintino Bocaiuva, Venâncio Ayres, José Bonifácio, Benjamin Constant, Silva Jardim, Saldanha Marinho, Prudente de Moraes, Marechal Deodoro. O fundador da antiga vila foi homenageado através da rua Barbosa Franco.

(7) - Oliveira, F. Pires de. ibidem, p. 277, 182, 283, 291. 
nagem ao fundador do povoado". Como este designativo recobre, formalmente, a estrutura hagiotoponímica, uma das mais concorridas na tessitura onomástica brasileira, vai aparecer também em outros pontos do território (Estados do Pará, Mato Grosso e Paraná). Faça-se, entretanto, uma ressalva a esta forma de se denominar: a precedência do nome do fundador do núcleo humano pelas partículas São ou Santo é bastante comum na toponímia do Brasil, e isso dificulta a classificação terminológica, pois empresta ao topônimo uma parência religiosa-devocional que nem sempre corresponde à realidade.

A cidade de Santos, apesar de sua procedência quinhentista, näo foi a primeira povoação fundada do litoral. Precedeu-a a vila de São Vicente, que remonta à época de Martim Afonso, e à qual estava ligada pela condição de servir-lhe de ancoradouro. E foi assim que Luis D'Alincourt a ela se referiu, ao estudar-lhe a denominação:

"ao princípio teve simplesmente o nome de Porto, querendo dizer que, era o Porto da Vila de $S$. Vicente; porque bem depressa os navegantes largaram o antigo ancoradouro; e vieram desembarcar os seus efeitos à nova povoação, donde eram conduzidos por terra à Vila, o que se thes fazia mais cómodo; (...). Assim se conservou a povoação por alguns anos até que o sobredito Braz Cubas fundou um Hospital junto à Casa de Misericordia para socorro dos marinheiros que adoeciam e lhe deu o apelido de Santos, à imitação de um semelhante em Lisboa. Este nome bem depressa se estendeu a toda a povoação, que até hoje se ficou chamando Porto de Santos" (8). (O grifo é nosso).

Não se quer, porém, aqui, discutir a origem de sua denominação e o acerto, ou não, da afirmativa de D'Alicourt, que envolveria, na hipótese, se exata, um problema de transplantação de topônimos e não de vinculação religiosa direta, como se poderia concluir da expressividade do sintagma em si. Assim, dentro da esquematização genérica deste artigo, em que fatos antropotoponímicos se sobrepõem como elementos necessários à configuração da própria história local, dois nomes de vilas distinguem-se na nomenclatura regional, porque envolvem as características discutidas: a vila Belmiro, anteriormente vila Operária, traz a denominação de seu fundador e benemérito, Dr. Belmiro Ribeiro de Moraes e Silva, e vila Matias, do nome do portugues Matias Casimiro Alberto da Costa, que doou várias glebas à Prefeitura de Santos para abertura de vias

(8) - D'Alicourt, Luis. Memória sobre a viagem do porto de Santos à cidade de Cuiabá. São Paulo, Publ. Comem. sob o alto patroc. da Com. do IV Centen. da Cid. de São Paulo, 1953, p. 27. 
públicas, tendo inaugurado o primitivo serviço de bondes da cidade. Uma outra denominação indiretamente de feitio religioso, mas que, na realidade, recobre traços antroponímicos, encontra-se na vila São Manuel, cujos loteadores pretenderam, no topônimo, fixar a lembrança do pai, Manuel de Souza Varela, muito ligado à benemerência .

Por outro lado, documentos dos mais antigos já se referem à existência de um porto na margem esquerda do Tietê, nas proximidades da Capela de Nossa Senhora da Candelaria de Utu'Guasso, nos primórdios do século XVII. Trata-se do porto de Araritaguaba, "o barreiro das araras", ponto de partida de Luis de Céspedes Xeria, em 1628, para a Ciudad Real de Guairá, e por ele denominado Nuestra Señora de Atocha. Desse local, sairiam continuadamente as chamadas expedições monçoeiras. o que fez com que, aos poucos, o primitivo nome fosse evoluindo para uma outra denominação, mais eufemística, e que melhor carreasse aos navegantes os bons augurios necessários a tão arriscadas travessias. $\mathrm{O}$ Tietê não era rio de fácil navegação. Os acidentes naturais de seu curso colocavam, lado a lado, como fatores ponderáveis, a habilidade dos pilo tos dos grandes batelões e a boa fortuna que toda a aventura requer. Por isso, Porto Feliz passou a ser cada vez mais e mais empregado pela população:

"à esquerda do Tietê, junto à cidade, há um porto, denominado Geral, que era antigamente o ponto de partida para as monções que, por conta do governo e de particulares, faziam-se para Mato Grosso em grandes canoas. Esse porto, que era para os viajantes o termo de grandes riscos e fadigas, foi naturalmente por eles qualificados de Felix, de onde procede a denominação do povoado desde que foi elevado à vila" (9).

Hoje, Araritaguaba é apenas referência histórica obrigatória a quem estuda o roteiro das viagens fluviais, não figurando mais no Indice dos topônimos; enquanto isso, o topônimo Porto Feliz, apesar da grande carga carismática de que se reveste, envolvido como está pela História, extrapolando a sua feição regional para assumir a marca da nacionalidade, vem repetido em outro acidente humano do Estado do Paraná, talvez por mero mimetismo.

Qualquer dos bairros da cidade de São Paulo, se examinado em seu plano urbano, fornecerá uma amostragem bastante significativa desta toponímia local, que se exaure em sua própria dimensionalidade.

(9) - "Relatório apresentado ao Exmo. Sr. Presidente da Provincia de São Paulo pela Comissão Central de Estatística, São Paulo, Leroy King Bookwalter, Tipografia King, 1888". Ins Soares de Souza, Jonas (org.) Araritaguaba: o Porto Feliz. Porto Feliz, Edição "Semana das Monções", 1979, p. 7. 
Na Penha, um dos marcos históricos da terra, com a célebre colina (10) de onde se avistava, já no Seiscentismo, o nascente burgo paulistano e os recortes dominantes de sua paisagem - as igrejas, os conventos e os mosteiros -, algumas de suas ruas evidenciam, paralelamente a outras origens, a sua motivação peculiar: a $P e$. Benedito Camargo homenageia aquele que foi, durante meio século, vigário de sua Paróquia; a Pe. Joâo (Batista Schamberger) lembra o religioso que substituiu o antigo vigário quando de sua morte; o Dr. João Ribeiro da Silva foi "um dos que subiram o rio Tietê num pequeno barco a vapor, estabelecendo residência na Penha"; a Cel. Rodovalho patenteia a figura do homem público que obteve do governo a "construção de um ramal entre a estação da Guaiaúna e as proximidades do largo da Igreja, onde se erguia a sua mansão"; a João Cesario recorda o "morador das proximidades do largo" (11). Já Amador Bueno da Veiga, que empresta seu nome à avenida localizada entre a rua Dr. João Ribeiro e a avenida São Miguel, muito embora tenha passado à história por seu desempenho em defesa dos interesses de São Paulo - foi "capitão-mor de S. Paulo e por seu prestígio mereceu ser eleito para comandar os paulistas na guerra contra os emboabas do Rio das Mortes (...). Em seu testamento doou ao colégio dos jesuítas de São Paulo vinte mil cruzados para que ele e sua mulher obtivessem o titulo de fundadores com os privilégios respectivos" (12) - pertence também à tradição do bairro, desde que suas terras encontravam-se em "Guarulhos, ao longo do rio Tietê, em ponto de junção daquele território com a Penha" (13).

Em Pinheiros, antiga aldeia indígena de 1560 , ao lado dos nomes de bandeirantes, sertanistas e primeiros colonos - como Antonio Bicudo, administrador das minas de ouro de Santa Fé, no Jaraguá, e que fez, segundo Pedro Taques, "muitas entradas ao sertão, adquirindo muito gentio de

(10) - A respeito do bairro da Penha e de suas vilas satélites, Aroldo de Azevedo interpretou-os como "uma individualidade própria", do ponto de vista geográfico. Essa individualidade, segundo ele, "lhes é dada, em primeiro lugar, pela geografia física: seu núcleo principal é constituido por uma elevação bem marcada - a colina da Penha, que se vê separada do centro urbano pela baixada do Aricanduva, por sua vez antecedida pela do Tatuapé, e da região da Cantareira pela vasta baixada do Tietê. Por outro lado, sua história faz com que ocupe um lugar à parte no meio da região em que se acha" (In: Subúrbios orientais de São Paulo. Tese de concurso à cadeira de Geografia do Brasil da FFCL da USP. São Paulo, 1945, p. 61).

(11) - Cf. fichários do Arquivo Municipal de São Paulo.

(12) - Azevedo Marques, Manoel Eufrasio de. Apontamentos históricos, geográfico. Essa individualidade, segundo ele, "lhes é dada, em primeiro lugar, comem. sob o patroc. da Com. do IV Centen. da Cid. de São Paulo. São Paulo, p. 45, T. I.

(13) - Cf. fichário do Arquivo Municipal de São Paulo. 
várias tribos, sendo certo que esteve no Guairá, em 1628" (14); Fernão Dias, "o Caçador de esmeraldas", "proprietário de larga extensão de terras que iam do Caaguaçu além dos Pinheiros, sítio denominado Capão" (15); Mateus Grou, "bandeirante de São Paulo que tomou parte na expedição de Jerônimo Pedroso de Barros ao Rio Grande do Sul, a qual sofreu grande revés no riacho Mbororé, tendo Mateus Álvares sido ferido por uma flechada, em 1641 (...)" (16); Simão Alvares - "bandeirante de São Paulo que tomou parte na destruição de Vila Rica do Guairá, de 1631 a 1632" (17); Garcia Rodrigues Velho, "grande bandeirante, descobridor de ouro em Curitiba (...). Passou depois aos descobrimentos de ouro nas Minas Gerais (...). Enlevado pela lenda do sertão das esmeraldas, obteve patente de capitão-mor de novos descobrimentos, nesse sentido, em 1711, sendo já bastante idoso" (18); João Pedroso de Morais, o "Terror dos Indios" que, com Fradique Coutinho e Mourato Coelho, participou da conquista de Guairá, sob a chefia de Antonio Raposo Tavares; além de Theodoro Sampaio, engenheiro, divulgador da língua o cultura tupis e fundador do Instituto Histórico da Bahia - alternam-se nomes evidenciadores da tradição local: Francisco Iasi, por exemplo, foi, por longos anos, morador e comerciante na região; o Cônego Eugenio Dias Leite, durante muito tempo, trabalhou na Paróquia de Nossa Senhora do Monte Serrate; Amaro Cavalheiro, historiador e incentivador da corporação musical do bairro; Pedro Christe, doador da área onde foi instalado - Mercado, então conhecido como "Mercado dos Caipiras", porque ali se vendia de tudo, desde mercadorias de consumo até propriedades agrícolas. Pedro Christe do Nascimento e sua mulher, Dona Maria Francisca de Oliveira, ao formalizarem a doação, na escritura pública levrada em 7 de dezembro de 1909, impuzeram como condição única a de que "o próprio seria de uso exclusivo dos produtores para venderem ao público suas mercadorias" e que "nunca sairia daquele local o Mercado, pois, caso contrário, reverteria o terreno para os herdeiros seus" (19).

O Brás, ponto intermediário e parada de descanso de quem vinha do Rio de Ianeiro para São Paulo, antes de se atingir a várzea do Carmo, era considerado um dos mais aprazíveis recantos da vila, com belas chácaras e residências. Uma delas, a do Ferrão, tornou-se célebre pela sua proprietária, a Marquesa de Santos, então casada com o Major-Brigadeiro

(14) - Carvalho Franco, Francisco de Assis. Dicionário de bandeirantes $e$ sertanistas do Brasil. São Paulo, Com. do IV Centen. da Cid. de São Paulo, 1954, p. 66.

(15) - Amaral, Antonio Barreto do, $O$ bairro de Pinheiros. São Paulo, Prefeit. Munic., Secret. de Educ, e Cult., Depto. de Cult., s/d, p. 124.

(16) - Carvalho Franco, Ibidem, p. 186.

(17) - Idem, Ibidem, p. 29.

(18) - Idem, Ibidem, p. 425.

(19) - Amaral, A. B. ibidem, p. 92. 
Rafael Tobias de Aguiar, de quem teve, entre outros, o filho Brasílico de Aguiar e Castro. Segundo a tradição, o topônimo do bairro provém da abreviatura de seu nome - Brás. Ao lado de uma toponímia diversificada, registram-se aí exemplos de nomes diretamente ligados à sua formação como núcleo urbano: Dr. Américo Brasiliense, vereador, depois Presidente da Provincia, propôs melhorias para as ruas do bairro; $D r$. Bresser, engenheiro alemão, autor de algumas das principais plantas da cidade de São Paulo do século passado, e "antigo proprietário da chácara Bresser, hoje cortada por numerosas ruas" (20); Lucas Queiroz de Assunção, "antigo proprietário e morador da zona em que se abre essa rua", anteriormente conhecida por Bresser do Lucas (21); Maria Marcolina Prado Monteiro, tradicional moradora do bairro; Monsenhor Anacleto Ribeiro Coutinho, "sacerdote benemérito dos desamparados, que os recolhia em sua casa, por volta de 1860"; Francisco Sampaio Moreira, "antigo comerciante em São Paulo, concorreu para o desenvolvimento do bairro" (22); viaduto Alberto Marino, maestro e figura muito conhecida, autor de duas músicas que se tornaram célebres: "A rapaziada do Brás" e "Senhoritas do Brás"; João Teodoro Xavier de Matos que, como Presidente da Província, elaborou o plano de ligação do Brás à Luz, em 1874. Dele, diz Paulo Cursino de Moura o seguinte:

"Urbanista na verdadeira acepção da palavra, remodelou quase completamente a cidade. Construiu a Rua do Conde d'Eu, hoje Rua Glicério, para ser, segundo o seu relatório, o caminho natural ... ao lugar histórico e memorável do Ipiranga (...). Embelezou e segurou o Morro do Carmo. Transformou os terrenos paludosos e miasmáticos da Várzea do Carmo, em frente ao velho mercado $(\ldots)$. Operou melhoramentos notáveis nas Ruas do Pari e do Gasômetro" (23).

E o que é mais notável a respeito desse homem público, cujos feitos extrapolaram os limites de uma zona, foi, como acentuou Cursino de Moura, o despojamento e a simplicidade, caracterizada pela evasão às pompas:

\footnotetext{
"Nunca teve uma divisa ou um título a aumentar-lhe o nome. Foi sempre e sempre será - João Teodoro - simples,
}

(20) - Cf. Fichário do Arquivo Municipal de São Paulo.

(21) - Cf. Fichário do Arquivo Municipal.

(22) - Cf. Fichário do Arquivo Municipal.

(23) - São Paulo de outrora (evocaşốes da metrópole). São Paulo, Edusp, 1980, p. 211. 
lacônico, aureolado pela gratidão e pelo respeito de um povo que o amou no passado (...)" (24).

A origem do nome de Santo Amaro prende-se à religiosidade cristã do casal João Paes e Suzana Rodrigues que, nos primeiros tempos da colonização de São Paulo, doou uma tosca imagem do santo, em madeira, à capela que se erguia na primitiva aldeia de índios do Ibirapuera, a Birapoera dos primeiros textos e documentos. Relativamente aos seus nomes de ruas, nota-se uma diferenciação antropotoponímica, pois, ao lado dos moradores tradicionais da região, alternam-se designativos como Anhanguera; Nicolau Barreto, bandeirante que, no século XVII, "organizou uma bandeira composta de cerca de trezentos brancos e mamelucos, alem de um corpo indígena, e sob a capa de descobrir ouro e prata, clesceu o rio Tietê e por essa via internou-se na região do baixo Paraná" (25); Jorge da Cruz, "sertanista de São Paulo, filho natural de Domingos Jorge Velho, segundo alguns, tomou parte na luta contra o gentio bravo e os palmares, no norte brasileiro" (26); Amador Bueno, "filho de Amador Bueno da Ribeira, foi bandeirante que fez diversas entradas ao sertão já para a conquista de índios, já para a pesquisa de minas. Em 1628, tomou parte na bandeira de Antonio Raposo Tavares ao Guairá" (27); Fernão Dias; Barão do Rio Branco; Duque de Caxias; João Alfredo; Senador José Bonifácio; Marechal Deodoro.

Entre aqueles nomes que remontam à história da região, incluam-se: Pires de Oliveira, "do governo municipal de Santo Amaro, no começo do século XIX; Prof. Renato Braga, "diretor do Grupo Escolar local, desde 1922, onde permaneceu por trinta anos"; Antonio das Chagas, "presidente da Comarca de Santo Amaro em 1813"; Adalberto de Andrade Pina, "participou da inauguração, em 1910, do Grupo Escolar de Santo Amaro, fazendo parte de seu corpo docente"; Ana Karlick, benemérita da região"; Angela Tanchella, "imigrante italiano no ano de 1895, desbravador da região e comerciante"; Pais da Silva, "membro do governo municipal de Santo Amaro, no início do século XIX.

No bairro de Santana, originário da antiga fazenda dos jesuítas, já no século XVII, a rua $D r$. Zuquim, antiga Carandiru, se destaca como uma das principais artérias. A denominação surgiu espontaneamente do próprio povo, segundo Gabriel Marques, em crônica publicada no jornal Folha da Noite, de 221 1958; médico, o Dr. Alfredo Zuquim das Neves era "um amigo da pobreza. Quanto mais pobre, mais ele se apressava

(24) - Ibidem, p. 212.

(25) - Carvalho Franco, lbidem, p. 52.

(26) - Idem, ibidem, p. 129.

(27) - Idem, ibidem, p. 82 
em acudir. Os pobres pagavam quanto pudessem. E os que não podiam pagar nada, não pagavam nada... E muitas e muitas vezes o pobre do Dr. Zuquim chegava a pagar os remédios com o dinheiro do seu bolso... Era um santo! Foi de justiça dar para a rua o nome dele".

Contrapondo-se à essa toponímia natural, nascida em consequiência de um dado comum ao morador do bairro, outra via importante, a Voluntários da Pátria, teve origem diferente. Sistematizada como historiotopônimo, prende-se à homenagem "ao $7^{\circ}$. batalhão de Voluntários da Pátria, incorporado ao $35^{\circ}$. do Corpo Geral, que partiu de São Paulo em julho de 1865 para combater as forças paraguaias" (28). A causa desses corpos combatentes pode ser assim resumida:

"Quando ao apresamento do "Marquês de Olinda" se seguiu a invasão do sul de Mato Grosso o governo imperial apelou para o patriotismo brasileiro.

Logo surgiu a idéia da formação de corpos de voluntários.

O Duque de Caxias, ouvido pelo governo sobre a melhor maneira de repelir a opressão, mostrou a conveniência da constuição de corpos provisórios. Recurso usado por diversas vezes no passado. Constituiam uma tradição. E alvitrou a denominação de Voluntários da Pátria.

(...) Um dos batalhões (de São Paulo) recebe a designação de $7^{\circ}$ de Voluntários da Pátria. Recebe uma bandeira bordada pelas senhoras paulistas. Irá cobrir-se de glória.

(...) $07^{\circ}$ esteve em Tucucué, Tuiuti, Surubuí, Angustura, Chaco, Vileta, Piquirici, Asunción, Luque. Não parou. Esteve presente em Taquaral e Cerro Corá.

Destacou-se em todos os combates pela valentia de seus integrantes. Seu valor foi reconhecido e ganhou fama. Em 19 de maio de 1866, o governo imperial agraciava a bandeira do $7 \circ$ de Voluntários da Pátria com a venera da Imperial Ordem do Cruzeiro" (29).

Um outro núcleo de ruas se inscreve, no bairro, dentre aqueles que relembram personalidades políticas de um modo geral, como o constituído pelas ruas Alfredo Pujol, Conselheiro Moreira de Barros, Conselheiro Pedro Luiz, Conselheiro Saraiva, General Ataliba Leonel, Mario Araujo, Olavo Egidio, Hermes da Fonseca.

(28) - Torres, Maria Celestina Teixeira Mendes. O bairro de Santana. São Paulo, Prefeit. Munic., Secret. de Educ. e Cult. Depart. de Cult.

(29) - Barros Ferreira, Miguel Ângelo. "A participação de São Paulo na guerra do Paraguai". In: Revista do Arquivo Municipal. São Paulo, vol. CLXXXIII, ano XXXIV, jan. a dez. de 1971, pp. 58, 59 e 64. 
Por outro lado, a proximidade do Campo de Marte justifica nomes como Aviador Gil Guilherme e Vasco Cinquim, "este um dos mais hábeis aviadores civis de São Paulo", além da rua da Aviação, designativo icônico por si só, desde que, conforme esclarecimentos prestados, foi aberta só para servir ao campo das proximidades do Tietê. Esses topônimos tendem, assim, por força de tal condicionante, a se transformar em elementos inerentes à tradição local, desde que, no meu entender, não teriam muita força expressiva fora da área onde se inscrevem.

Mesmo um estudo de microtoponímia como este, não comportaria, no momento, a viabilização de todos os seus aspectos e principais formantes. São Paulo possui cerca de 571 municípios e o planalto paulistano estende-se por uma área aproximada de 5.000 quilômetros quadrados, repartidos em inúmeros bairros, vilas, parques e jardins. Por aí se vê que a análise global dos topônimos compreendidos nessa espacialidade demandaria estudos mais profundos, que escapariam à finalidade imediata do presente artigo. De qualquer forma, os exemplos aqui mencionados devem ser entendidos como uma amostragem do que se está realizando em nível mais amplo. 